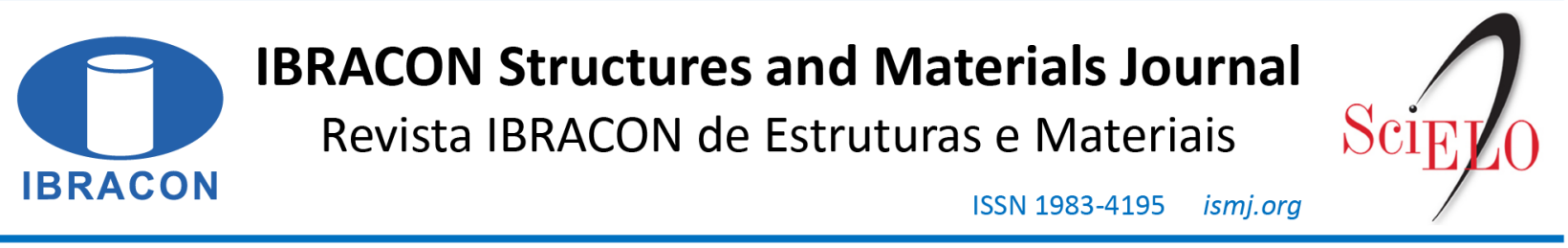

ORIGINAL ARTICLE

\title{
Nonlinear finite element analysis of reinforced concrete shear walls
}

\section{Análise não-linear de pilares-parede de concreto armado via método dos elementos finitos}

\author{
Jordlly Reydson de Barros Silva ${ }^{\mathrm{a}, \mathrm{b}}$ (i) \\ Bernardo Horowitz ${ }^{\mathrm{b}}$ (D)
}

${ }^{a}$ Universidade Federal Rural de Pernambuco - UFRPE, Unidade Acadêmica do Cabo de Santo Agostinho - UACSA, Cabo de Santo Agostinho, PE, Brasil

${ }^{b}$ Universidade Federal de Pernambuco - UFPE, Programa de Pós-graduação em Engenharia Civil, Departamento de Engenharia Civil, Recife, PE, Brasil

Received 04 November 2019 Accepted 11 March 2020

\begin{abstract}
This paper deals with a fundamental issue for tall buildings safety: the structural analysis of reinforced concrete shear-walls that resist lateral loads. For two shear walls (simple planar and U-shaped), the results determined according to the Brazilian design code approximate procedure (NBR-6118:2014) and the grid method (CAD/TQS), presented in the literature, are compared with material and geometrically nonlinear finite shell element analysis (NL-FEA), performed by the software VecTor 4, based on the modified compression field theory (MCFT). In both cases NL-FEA analyses, besides the large computational cost, it was observed the significant influence of stress redistribution, and the Saint-Venant's principle, on the vertical normal stresses, and the consequent smoothing of the second order localized effects on the shear walls.
\end{abstract}

Keywords: shear walls, reinforced concrete, finite element, nonlinear analysis.

Resumo: O presente artigo trata de um tema fundamental para a segurança de edificações de altura elevada: a adequada avaliação do comportamento dos pilares-parede de concreto armado, que compõem a estrutura de contraventamento da construção. Para dois pilares-parede (simples e seção U), os resultados obtidos segundo o método simplificado (NBR-6118:2014) e o método da malha de barras (CAD/TQS), presentes na literatura, são comparados com análises não-lineares (física e geométrica) com elementos finitos de casca (MEF-NL), realizadas no software VecTor 4, o qual é baseado na teoria do campo de compressão modificada. Com isso, nos dois casos, nas análises via MEF-NL, além do considerável custo computacional, foi possível notar a significativa influência do efeito da redistribuição dos esforços, e do princípio de Saint-Venant, nas tensões normais verticais, o que contribuiu para a atenuação dos efeitos localizados de $2^{\mathrm{a}}$ ordem nos pilares-parede, em relação ao observado na literatura.

Palavras-chave: pilares-parede, concreto armado, elementos finitos, análise não-linear.

How to cite: J. R. B. Silva and B. Horowitz, "Nonlinear finite element analysis of reinforced concrete shear walls," Rev. IBRACON Estrut. Mater., vol. 13, no. 6, e13603, 2020, https://doi.org/10.1590/S1983-41952020000600003

\section{INTRODUCTION}

In the recent decades, it has become evident the increasing number of reinforced concrete tall-buildings. Although it's associated with an efficient occupation of the urban land, and consequently promotes economic benefits, it results in several technical challenges. These issues are been overcome due to scientific advances in several fields, such as concrete technology and structural analysis.

One of the main steps in the reinforced concrete tall-building design that has been influenced by this verticalization process is the global structural stability analysis, which is related to the building lateral loads, such as wind seismic loads. 
According to Wight and MacGregor [1], in buildings up to 8 to 10 stories, the global stability can be guaranteed using a rigid frame system. On the other hand, when a building exceeds this limit, and especially when the structure is subject to earthquakes, the rigid system may not be enough, and shear walls can be used as lateral load-resisting system.

According to the Brazilian reinforced concrete design code, NBR-6118:2014 [2], in shear walls structural design, it's not necessary to calculate only global and local second order effects, as occur to conventional columns. It may also be necessary to take into account in the analysis the so-called second order localized effects. In the code's item 15.9.3, an approximate procedure for calculating these additional internal forces is presented. Although this model has been valid since NBR-6118:2003, it have not received general acceptance by the technical community, among other reasons, for not providing an adequate recommendation for shear walls transverse reinforcement. The code model limitations have motivated the development of alternative shear walls design procedures [3].

This paper presents, for two shear walls (simple planar and U-shaped), a comparative study between the structures behavior according to the Brazilian design code approximate procedure [2], the grid method [3], presented in the technical literature, and material and geometric nonlinear finite shell element analysis (NL-FEA), performed by VecTor 4 software, based on the Modified Compression Field Theory (MCFT) [4]. The U-shaped shear wall analysis was performed in order to consider the structure main buckling modes.

\section{SHEAR WALLS AND SECORD ORDER LOCALIZED EFFECTS}

NBR-6118:2014 [2] defines a shear wall as a vertical planar element mainly subjected to in-plane compression, where the structure cross-section dimensions have a relationship between the largest and the smallest dimensions greater than 5. Figure 1 illustrates the geometry and the use of a shear wall in a real reinforced concrete (RC) building [5].
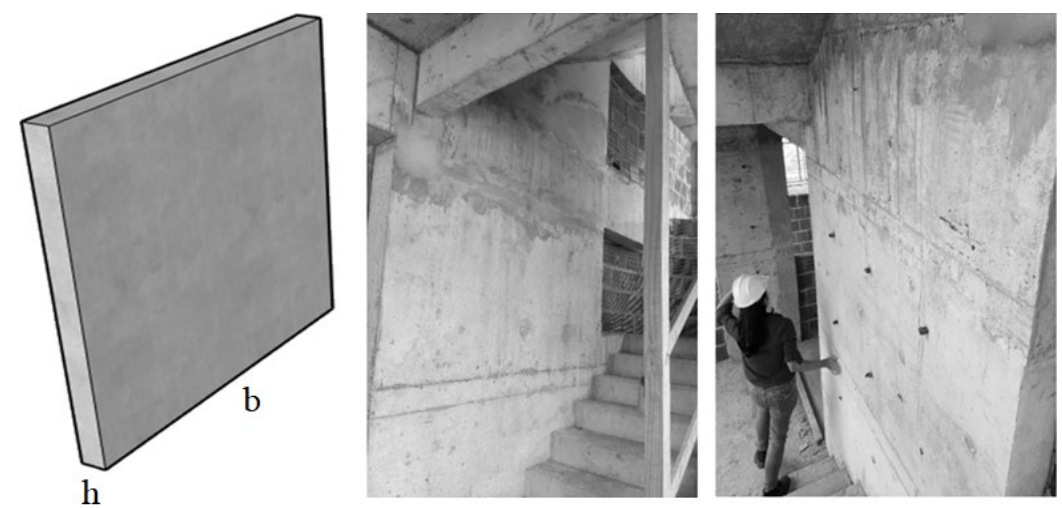

Figure 1. Simple planar shear wall geometry and its use in a RC building [5]
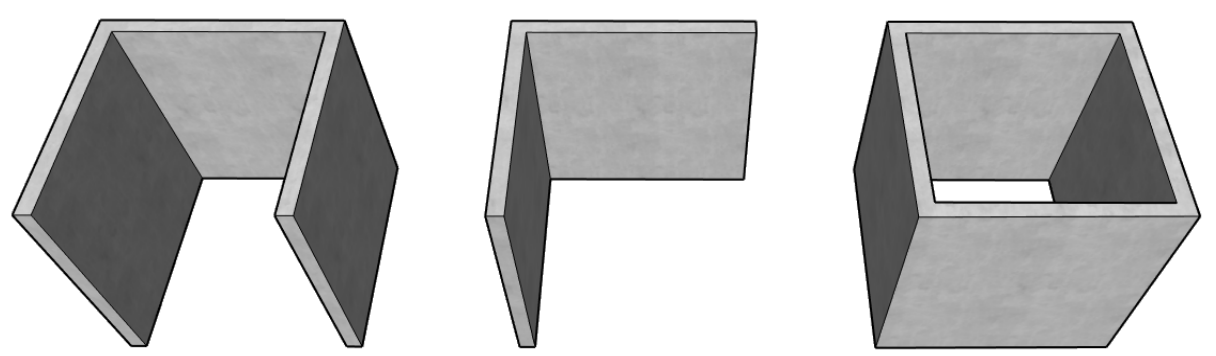

Figure 2. Assembled shear walls: U-shaped, L-shaped and closed cross-section shear walls

According to the case, in order to increase the system structural strength, it is usual to combine several planar wall segments, resulting in wall assemblies. Figure 2 shows three cases of wall assemblies, two open cross-sections (Ushaped and L-shaped) and a closed cross-section, usually used in bridge columns.

Due to the difficulty of allocate the shear walls in the building architectural project, these elements usually can be found around the elevator shaft or the stairs [1]. Figure 3 illustrates the arrangement of these elements in a structural project [6]. 


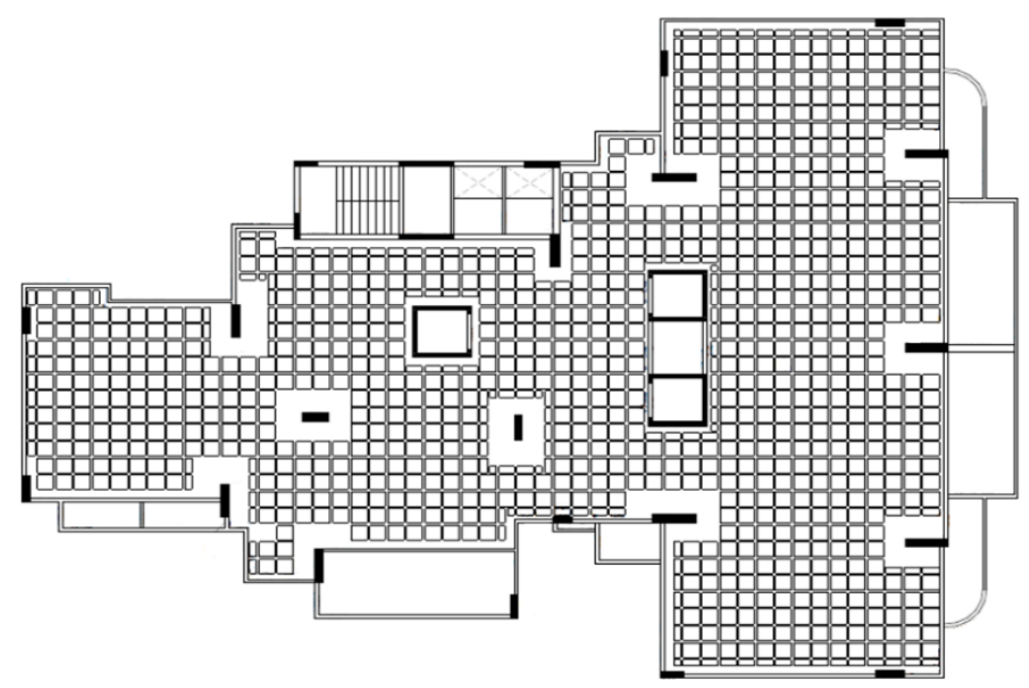

Figure 3. Shear walls arrangement on a building project [6]

\subsection{Shear walls subjected to seismic loads}

Currently, the structural analysis and design of reinforced concrete shear walls has become a usual object of scientific research around the world, especially after recent earthquakes that occurred in Chile (2010) and New Zealand (2011), which caused several structural damages in these elements [6].

However, according to relevant technical codes [7], the majority of the Brazilian territory, especially the most densely populated territories, with a larger number of tall buildings potentially subject to considerable horizontal forces, is located in a low seismic hazard region. Thus, unlike other countries, the main horizontal load acting in Brazilian buildings are wind loads, not seismic loads [6].

Thus, due to low seismic risk, in contrast to other parts of the world, there is a trend for shear walls to have thinner thickness than foreign ones, and, consequently, to be more susceptible to instabilities. This situation is aggravated by the concrete technology evolution, which allows the use of slender walls. Therefore, it becomes evident the necessity of research that reflect the Brazilian engineering situation.

\subsection{Second order localized effects}

As mentioned previously, in shear walls structural design, besides the global and local second order effects, common in the analysis of usual columns, it is also necessary evaluate the so-called second order localized effects, Figure 4 . This phenomenon can be defined as a lateral instability, in certain regions of the shear wall, so that the resulting displacements cause additional second order internal forces in the structure.

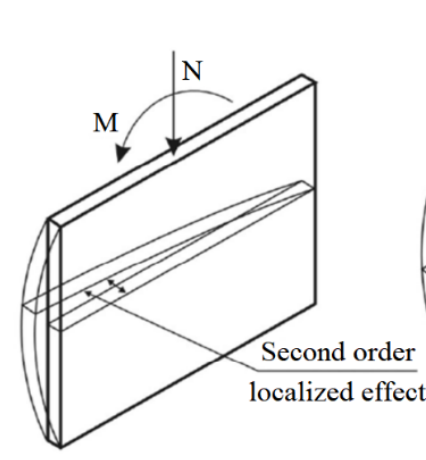

(a) Simple planar shear wall second order localized effect
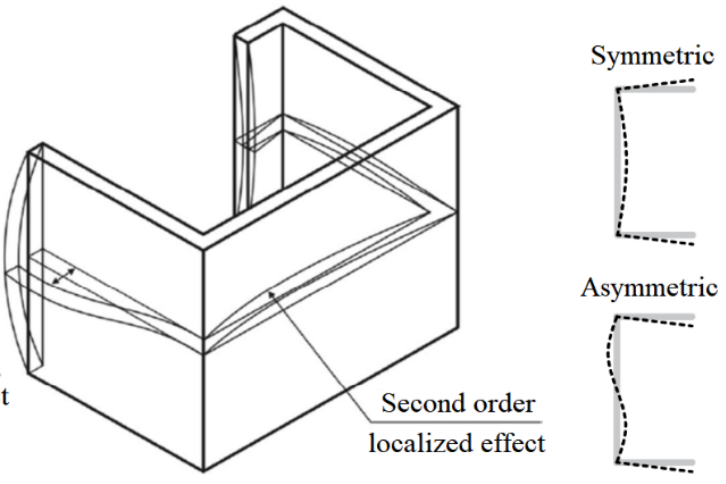

(b) U-shaped shear wall second order localized effect (c) U-shaped shear wall two possible buckling modes

Figure 4. Shear walls second order localized effects and buckling modes [2] 
The second order localized effect produces not only an increase in the wall longitudinal bending moment (tension in the vertical direction), but also a curvature in the horizontal direction, therefore, it's necessary to consider provision of reinforcement in that direction too (transverse reinforcement).

In addition, for a properly shear wall structural analysis, evaluating the second order localized effects, it's necessary to appropriately consider the structure buckling modes. This issue is of particular importance in the structural stability of thin-walled open sections, like U-shaped shear walls. Figure 4c illustrates two possible buckling modes for this kind of problem.

\subsection{Brazilian code criteria for the consideration of second order localized effects}

According to NBR-6118:2014 [2], the shear walls second order localized effects may be neglected if, for each of the planar segment that composes the shear wall, the following conditions are satisfied:

- The superior and inferior edge of each planar wall segments must be restrained by the slabs, which produces a horizontal diaphragm effect;

- The slenderness ratio of each planar segment $\lambda_{j}$ must satisfy Equation 1 .

$\lambda_{j}=3.46 \frac{l_{e j}}{h_{j}}<35$

where, $h_{j}$ is the thickness of the wall $j$ and $l_{e j}$ is the wall equivalent length, which depends on the structure boundary conditions. Figure 5 illustrates some possible boundary conditions, where $l$ and $b$ are, respectively, the vertical free length and the wall largest cross-section dimension. Consulting Figure 5 and Table 1, it is possible to determine the equivalent length in each planar segment that composes the shear wall.
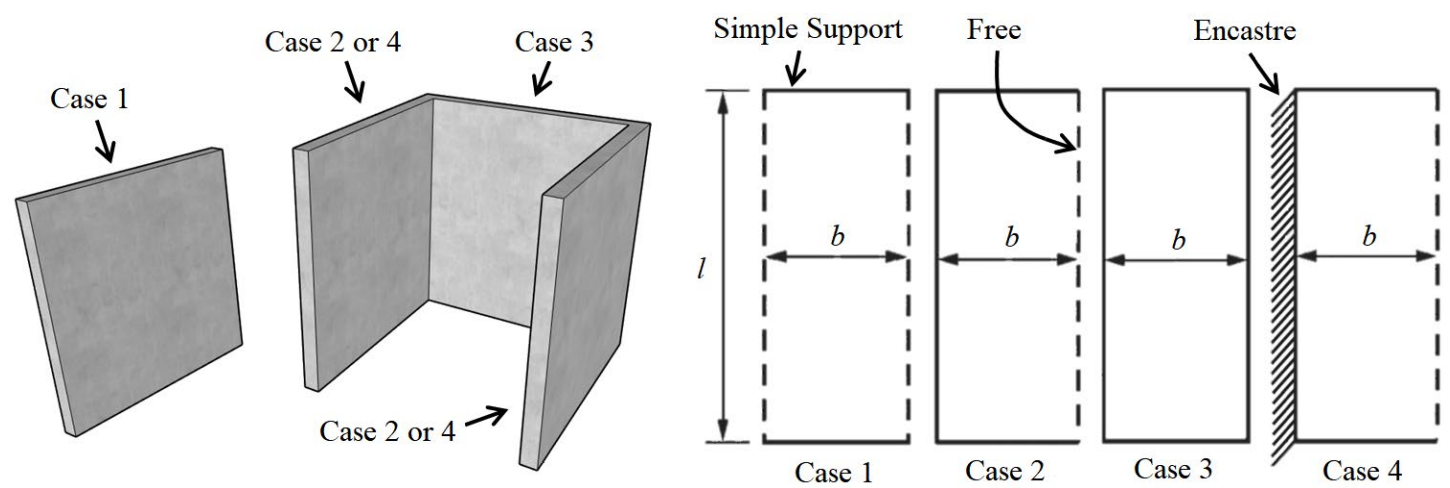

Figure 5. Walls boundary conditions cases [2], [3]

Table 1. Planar wall equivalent length.

\begin{tabular}{|c|c|}
\hline Boundary conditions cases & Planar wall equivalent length equations \\
\hline Case 1 & $l_{e}=l$ \\
\hline Case 2 & $l_{e}=\frac{l}{1+\left(\frac{l}{3 b}\right)^{2}} \geq 0.3 l$ \\
\hline Case 3 & $l_{e}=\left\{\begin{array}{c}\frac{l}{1+\left(\frac{l}{b}\right)^{2}} \text { sel } \leq b \\
\frac{b}{2} s e l>b\end{array}\right.$ \\
\hline Case 4 & $l_{e}=2 b \leq l$ \\
\hline
\end{tabular}




\subsection{Brazilian code approximate procedure to second order localized effects analysis}

According to NBR-6118:2014 [2], shear walls with slenderness ratios $\lambda_{j}$ lower than 90, in each of their planar wall components, can be analyzed according to an approximate procedure. This model idealizes each wall as a set of $i$ vertical frames and analyze the frames as independent columns subject to equivalent bending $M_{y d i}$ and compression $N_{i}$ loads, Figure 6. This procedure assumes that the equivalent width of each vertical frame $a_{i}$ must satisfy the condition of Equation 2.

$a_{i}=3 h<100 \mathrm{~cm}$
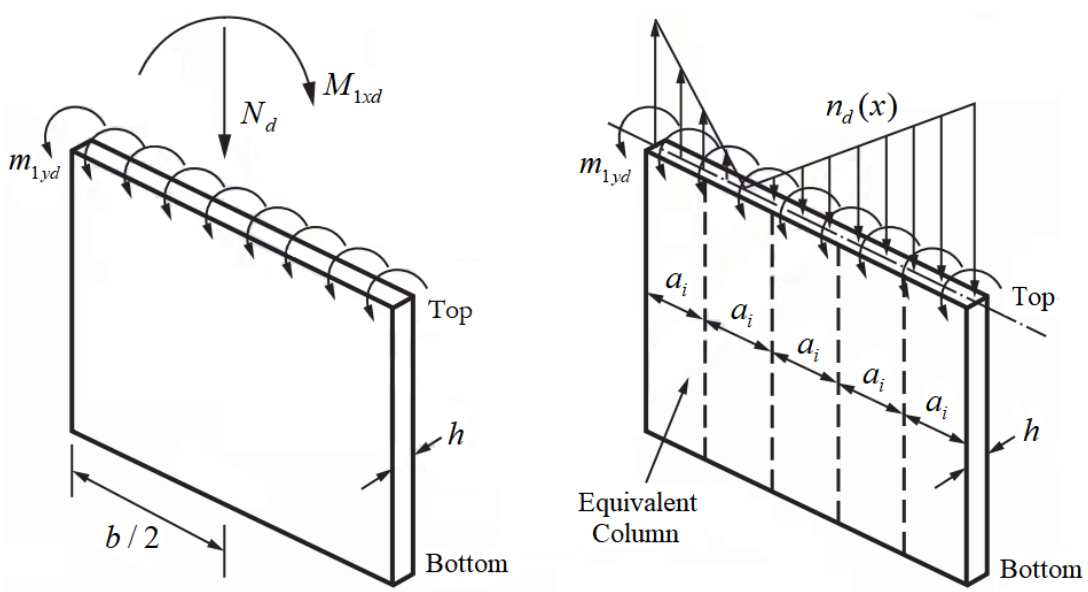

Figure 6. Brazilian code approximate procedure: wall discretization [2], [3]

The compression load $N_{i}$ is calculated from the resulting compression stress over the wall largest dimension, Figure 6, and the moment $M_{y d i}$ can be obtained according to the column width $a_{i}$ and the bending moment $m_{y d}$ in the smallest wall cross-section dimension, Equation 3.

$M_{y d i}=m_{l y d} a_{i}$

In addition, it must be ensured that the bending moment applied according to the frame smallest dimension must be greater than the first order minimum moment $M_{y d i} \geq M_{I d, \text { min }}$, when the latter is adopted in the geometric imperfections analysis. On the other hand, when $M_{y d i}<M_{l d, \min }$, it is not necessary to adopt local analysis coefficients greater than 0.6 , in the equivalent columns model [2], [6].

Based on this approximate procedure, the shear walls second order localized effects are evaluated using the equivalent columns second order local effects.

This approximate procedure is based on one of the structural analysis main principles: trying to understand the behavior of a complex construction based on the association of simpler elements. This principle is well known and used in the technical community, and it has resulted in several analysis procedures. Nevertheless, this procedure has been heavily criticized in the professional and academic fields [6], for example, according to Araújo [8], this procedure has no consistent experimental or theoretical justification, and leads the design to major increases in longitudinal reinforcement.

Other points that received criticism include:

- The Brazilian code does not specify what to do when the planar wall segments have slenderness ratios $\lambda_{j}$ greater than 90;

- The code's item 18.5 recommends that if the wall transverse bending moment is not calculated (as the approximate procedure does), the wall transverse reinforcement should be greater that $25 \%$ of the wall longitudinal 
reinforcement. According to França and Kimura [3], in some cases, this amount of reinforcement may be excessive, while in others it could be insufficient.

Thus, it is evident that the Brazilian code approximate procedure to shear wall second order localized effects analysis demands future contributions, so that it could be sufficiently precise and simple to apply, ideal for day-to-day work in project offices.

\subsection{Grid method to second order localized effects analysis}

In order to present an alternative procedure for shear wall second order localized effects analysis, França and Kimura [3] proposed a model, in which the shear wall is discretized in a bar mesh, like a grid. In this model, the physical nonlinearity is considered using the bars secant stiffnesses, according to axial-bending-curvature (N-M-1/r) diagrams. The geometric nonlinearity is evaluated through an iterative procedure, until displacement convergence.

One great advantage of the grid method in relation to the approximate procedure is that by providing bars in the horizontal direction, it can capture bending moments in this direction, which can be used in a more accurate design of the transverse reinforcement, instead of the arbitrary $25 \%$ of the longitudinal reinforcement, as indicated by the Brazilian code.

\section{NONLINEAR FINITE ELEMENT ANALYSIS}

\subsection{Shear walls analyzed}

As previously mentioned in this paper, two usual shear walls were selected for a comparative study between the two methods mentioned above and a nonlinear finite shell element analysis (NL-FEA). These two structures are a simple planar shear-wall (rectangular cross-section) and a U-shaped shear wall, both presented in the literature [3], [9], [10]. Figure 7 shows the structures geometry and loads. It was considered concrete C30, reinforcement cover equal to $30 \mathrm{~mm}$ and CA-50 steel reinforcement. In addition, all the planar wall segments were considered simply supported at the superior and inferior edges.

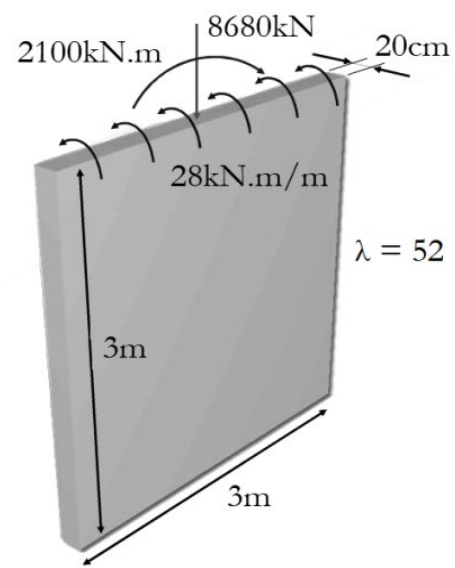

(a) Simple planar shear wall loads and geometry

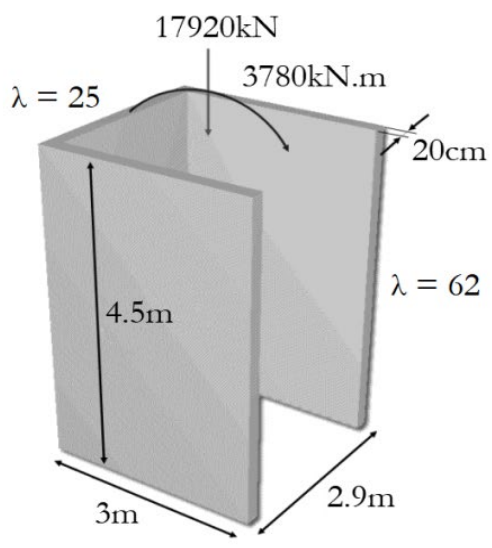

(b) U-shaped shear wall loads and geometry

Figure 7. Shear walls loads and geometry [3], [9], [10]

\subsection{Structural analysis software}

In this paper, it was used the VecTor 4 structural analysis software (version 4.30, Jan. 2019). It is a nonlinear finite shell element analysis software of reinforced concrete structures such as shells, slabs, walls, in quasi-static and dynamic problems. This tool has been developed at the University of Toronto, Canada, since the 1980s and has received other previous names [4]. VecTor 4 can be used jointly with the software FormWorks + and Janus, respectively, finite element analysis pre-processor and post-processor, both also developed at the same university. According to Hrynyk [4], VecTor 
4 formulation uses a degenerated shell finite element, in other words, a shell element developed directly from threedimensional elasticity equations, instead of using shell theories, and, that is one of the most common approaches in shell structures modeling. It is a quadrilateral 9-nodes shell, with a total of 42 degrees of freedom ( 3 translations in each direction, and two rotations, in the 8 edge nodes, Figure $8 \mathrm{~b}$ ). The element is also classified as a heterosis element because it uses in its formulation a combination of lagrangian and serendipity shape functions. In addition, this element is discretized in layers, so it could be possible to consider the variation in the internal stress along the thickness of the structure, both in thin and thick shells, Figure 8a. Further details about the 9-node heterosis degenerate shell element, implemented in VecTor 4, can be found in the literature [4], [11], [12].

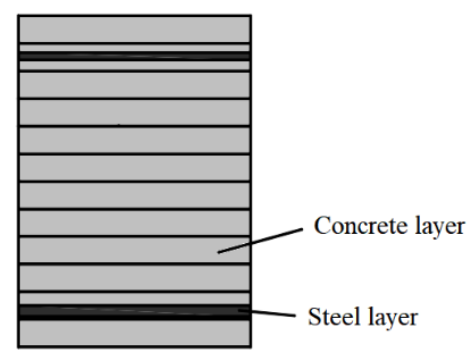

(a) Layers and stress distribution through shell thickness

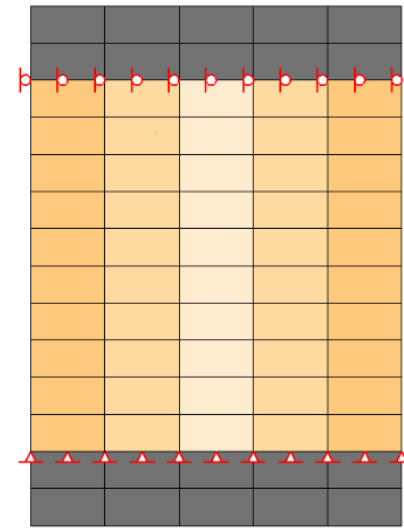

(c) Simple planar wall finite element mesh

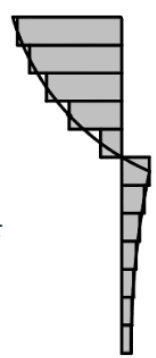

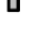 \\ (1)}

\section{(1)}

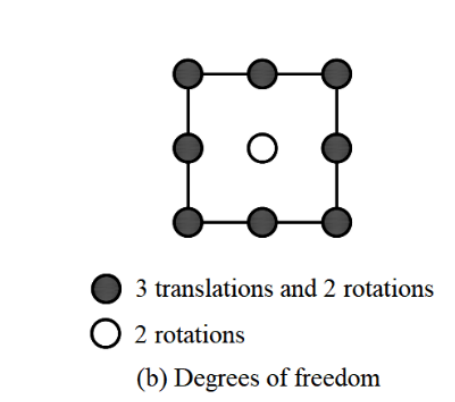

(b) Degrees of freedom

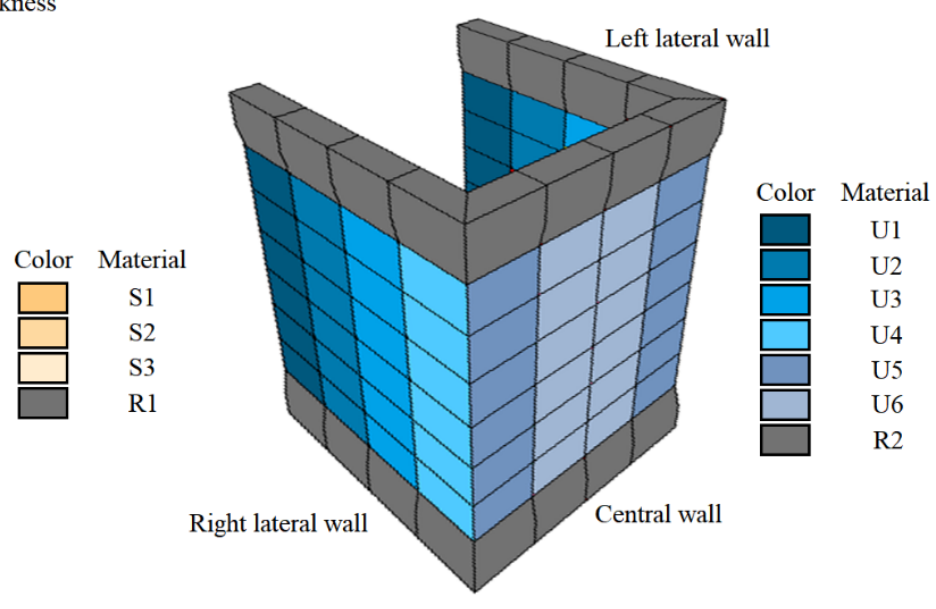

(d) U-shaped shear wall finite element mesh

Figure 8. Shear walls finite element modeling [4]

One of the main factors that made VecTor 4 be chosen to this study was the constitutive modeling of reinforced concrete. As previously mentioned, this program is based on the well-known Modified Compression Field Theory (MCFT), one of the most accepted formulations by the technical community for reinforced concrete modeling. According to Hrynyk [4], the MCFT can be used to predict the behavior of reinforced concrete structures subjected to biaxial loads conditions. This formulation was published by Vecchio and Collins [13] in the 1980s, and has been studied since then. The MCFT idealizes cracked reinforced concrete as a new orthotropic material, with built-in reinforcement, subject to its own constitutive relationships. It considers the concrete compression softening and concrete tensile stiffening effects [4]. In addition, some of the main fundamentals of this model are:

- Transverse and longitudinal reinforcements are considered uniformly distributed throughout the element;

- The cracks are smeared across the concrete element and its orientation is free to rotate, according to variations in the applied loads and materials response;

- It is considered the average stresses and strains in regions containing several cracks;

- Independent constitutive relationships are used for concrete and steel;

- The principal stresses and strains axes are coincident. 
In addition, according to Hrynyk [4], VecTor 4 also uses, in its formulation, the Disturbed Stress Field Model (DSFM). In general, the DSFM is an extension of the MCFT, which admits disagreements between the principal stresses and strains axes [4]. The DSFM was proposed by Vecchio [14] in order to solve some limitations of the MCFT in correctly predicting the behavior of high and low reinforcement rates element strength and stiffness.

Additional information and details about these two models and their implementation in VecTor 4 can be found in the technical literature [4], [11]-[14].

\subsection{Finite element modeling criteria}

This section details the main criteria used in the shear walls finite element modeling, using VecTor 4 and its preprocessor FormWorks+.

The external loads were applied as equivalent nodal forces and moments, concentrated at the nodes, in a similar way to what the Brazilian code approximate procedure indicates. The magnitudes of these nodal forces and moments were obtained considering the total loads indicated in Figure 7, the stress distribution, Figure 6, and each node influence area.

In addition to the external loads, in order to induce the behavior of the U-shaped shear wall to a specific buckling mode, two more nodal forces (induction loads) were applied in the midpoints of the two lateral planar wall segments free edges, perpendicular to the wall plan. When the symmetric buckling mode is analyzed, the two loads have opposite orientation (pointing towards the center of the structure). On the other hand, when the asymmetric buckling mode is analyzed, the two loads have the same orientation. The magnitude of these additional forces was defined in a way that it was sufficient to cause small transverse displacements in the lateral planar walls, equal to $1 / 20.000$ of the wall height. In this evaluation, a $60 \mathrm{~cm}$ width strip of lateral planar wall was considered ( $3 \mathrm{x}$ wall thickness, as recommended by the Brazilian code approximate procedure). Thus, the magnitude of the induction loads was found about $1.5 \mathrm{kN}$, approximately $0.3 \%$ of the lowest external nodal load. It is important to note that, if this or other similar criteria had not been adopted in the analysis, the lateral displacement pattern obtained could be significantly influenced by residual errors of the numerical solution procedure.

In order to avoid artificial stress concentration due to the load application process adopted, it was decided to use rigid elements on the loaded and supported edges, as an extension of the shear wall, in order to regularize the structure behavior in these regions. Figure 8 illustrates these rigid elements (R1 and R2), on the top and bottom edges of the structures.

As mentioned previously, the finite element meshes adopted heterosis degenerate elements. Figure $8 \mathrm{c}$ illustrates the first shear wall mesh geometry, which is composed of 5x14 square elements (elements dimensions $=60 \times 30 \mathrm{~cm}$ ). The top and the bottom elements consist of auxiliary rigid elements (R1), with thickness equal to $50 \mathrm{~cm}$. According to Figure $8 \mathrm{~d}$, it is possible to notice that the U-shaped shear wall was discretized in the vertical direction in 6 elements and in two more rows, referring to rigid elements (R2), with thickness equal to $30 \mathrm{~cm}$, at the superior and inferior edges. In the horizontal plane, 4 elements were applied in the central planar wall and 4 in each of the lateral planar walls. All elements on the lateral planar wall elements (including rigid ones) were $75 \times 75 \mathrm{~cm}$, while those in the central region were $72.5 \times 75 \mathrm{~cm}$.

In addition, due to the fact that the VecTor 4 finite element does not consider the drilling degrees of freedom (DOF), unlike other formulations, to ensure compatibility between the elements DOF at the connection between the laterals and the central walls, in the U-shaped shear wall, it was necessary to model this connection in a three-dimensional way, through a trapezoidal configuration of the elements involved, Figure 8d. This is a peculiarity of the software which despite modeling difficulties, reduces the number of degrees of freedom and contributes to computational efficiency.

It is important to note that, despite the symmetry of the U-shaped shear wall loads and geometry, it is not appropriate to consider this fact of the problem in the analysis, by modeling only half of the structure. Even if this meant a considerable reduction in the computational cost, the model would neglect the possible asymmetric buckling modes, Figure 4c, which can have considerable importance in the structure behavior.

As presented in section 3.1, the walls were considered simply supported. Thus, first and second shear walls were hinged supports at the lower edge (restricting all the translation degrees of freedom), and at the upper edge, the nodes translation degrees of freedom in the horizontal plane were restricted, Figure 8c.

In order to take into account the problem material non-linearity, it was necessary to consider the reinforcement presented in each shear wall. It was decided to adopt in this paper the reinforcement obtained in the literature [3], [10], using the Brazilian code approximate procedure [2]. According to the longitudinal reinforcement associated with the position of each finite element, an equivalent steel rate was defined in each of them, Figure 9. In both shear walls, the transverse reinforcement adopted was $25 \%$ of the longitudinal steel ratio, as recommended by NBR-6118:2014, respectively, 5.80 and $2.78 \mathrm{~cm}^{2} / \mathrm{m}$, per face, in the first and second shear wall. It is important to note that, due to the discretization of the layered shell element, the reinforcements could be arranged in the model in their appropriate 
positions, according to the cover and bar thickness. In the two structures, a total of 19 layers were adopted: 15 concrete, 2 longitudinal steel and 2 for the transverse steel layers.

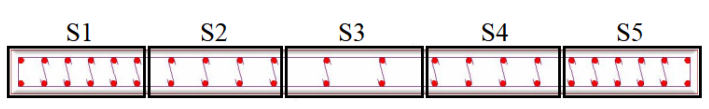

$\mathrm{S} 1: 2 \mathrm{x} 6020 \mathrm{~mm}$

$\mathrm{S} 2: 4 \times 4 \phi 20 \mathrm{~mm}$

S3: $2 \times 2 \phi 20 \mathrm{~mm}$

(a) Simple planar shear wall

longitudinal reinforcement

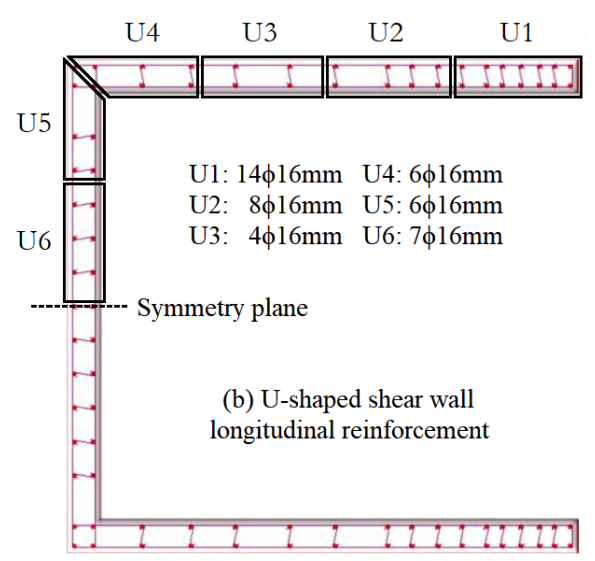

(b) U-shaped shear wall

longitudinal reinforcement

Figure 9. Shear walls longitudinal reinforcements [3], [10]

It was decided to adopt the software standard configurations for concrete and steel constitutive models, as recommended by Hrynyk [4], for most kind of problems analyzes in VecTor 4. Among these models, we can highlight:

- The well-known Hognestad parabola and the modified Park-Kent model [15], respectively, for pre-peak and postpeak concrete in compression;

- For the compression softening and the concrete tensile stiffening, in that order, the models known as Vecchio 1992A and modified Bentz 2003, described in Wong et al. [16], and;

- Seckin's model [17], for the steel hysteretic behavior.

The development of appropriate constitutive models for each kind of problem is a current research field, given the significant influence they have on the accuracy of the results obtained. Thus, further studies are needed to verify which would be the most adequate constitutive relationships in the analysis of shear walls similar to those presented in this paper.

Finally, the iterative-incremental procedure adopted to solve the nonlinear finite element problems used 100 loading stages, with a load step increase equivalent to $1 \%$ of the total load. In addition, the load stage maximum number of iterations and the analysis convergence tolerance were defined, respectively, as 100 and $10^{-5}$.

\section{RESULTS AND DISCUSSIONS}

This section is dedicated to presenting the main results obtained in the shear walls NL-FEA, as well as compare the internal forces obtained with their respective values according the Brazilian design code approximate procedure [2] and the grid method [3], [10].

In Figures 10, 11 and 12, it is possible to see the displacements and internal forces diagrams (without the rigid elements), respectively, of the simple planar and the U-shaped shear wall two buckling modes. In these illustrations, the displacements were obtained based on the VecTor 4 post-processor, Janus, while the diagrams were determined according to the internal forces provided by VecTor 4, at the Gauss points of each finite element, and a Python postprocessing routine, written by the authors. In addition, Tables 2 and 3 compare the maximum bending moments obtained in the two structures, according to the three analyses procedure presented.

\subsection{Simple planar shear wall analysis results}

In the simple planar shear wall analysis, it was possible to observe that, close to the load application region (upper edge), the elements axial stress in the vertical direction $N_{Y Y}$, are practically the same values found according to the literature results. However, as the study point distances from the loads, the distribution of this stresses tends to become 
more uniform across the cross section, as described by the Saint-Venant principle, Figure 10d, a fact not observed in the grid model or in the Brazilian code approximate procedure.

The maximum longitudinal bending moment (tension in the vertical direction) $M_{Y Y}$ is located in an element in the less vertically loaded side of the wall (left side), Figure 10e. This behavior disagrees with the literature models, which consider the maximum $M_{Y Y}$ located on the right edge, due to the greater compression stress and the appearance of second order localized effects associated with it, Table 2. Thus, at first sight, the result obtained is counterintuitive. However, after investigations, the following possible justifications can be highlighted:

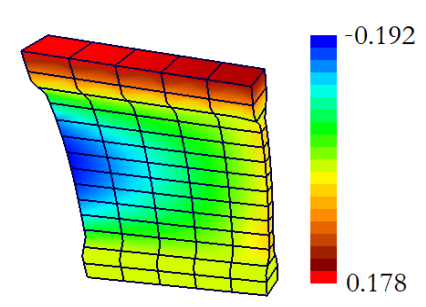

(a) Diplacement X (mm)

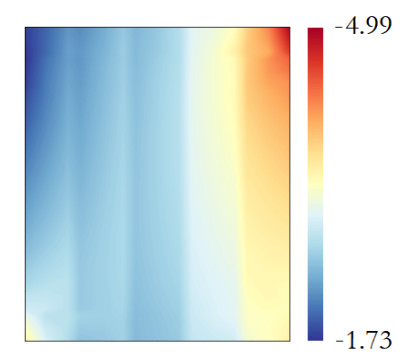

(d) Vertical normal force $(\mathrm{MN} / \mathrm{m})$

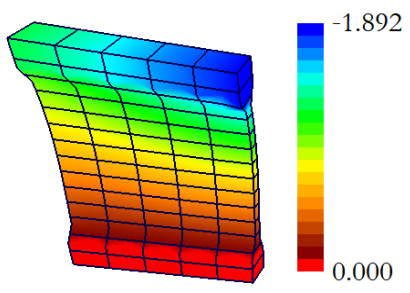

(b) Displacement Y (mm)

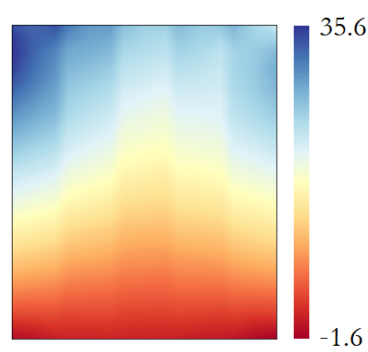

(e) Longitudinal bending moment $(\mathrm{kN} . \mathrm{m} / \mathrm{m})$

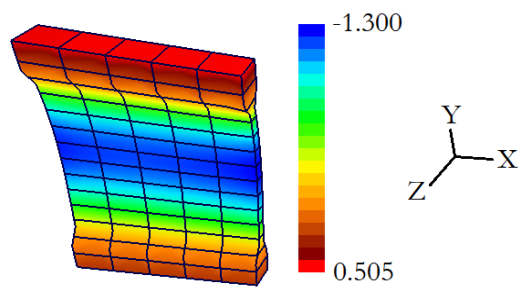

(c) Displacement Z (mm)

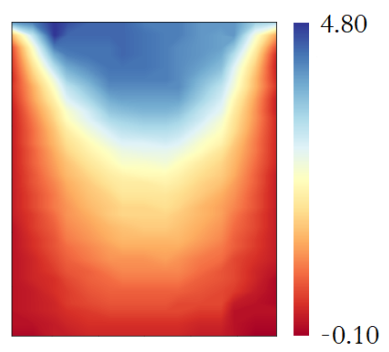

(f) Transverse bending moment $(\mathrm{kN} . \mathrm{m} / \mathrm{m})$

Figure 10. Simple planar shear wall displacements and internal forces diagrams

Table 2 Simple planar shear wall maximum bending moments $(\mathrm{kN} \cdot \mathrm{m} / \mathrm{m})$.

\begin{tabular}{cccc}
\hline & $\begin{array}{c}\text { Longitudinal bending moment } \\
\boldsymbol{M}_{\boldsymbol{Y}} \text { (left edge) }\end{array}$ & $\begin{array}{c}\text { Longitudinal bending moment } \\
\boldsymbol{M}_{\boldsymbol{Y}} \text { (right edge) }\end{array}$ & $\begin{array}{c}\text { Transverse bending } \\
\text { moment }^{\boldsymbol{M}_{\boldsymbol{X} \boldsymbol{X}}}\end{array}$ \\
\hline $\begin{array}{c}\text { Brazilian code } \\
\text { approximate procedure [3] }\end{array}$ & - & $55.2 *$ & - \\
\hline Grid method [3], [10] & $33.6^{*}$ & $48.8 *$ & 1.7 \\
\hline VecTor 4 NL-FEA & 35.6 & 27.9 & 4.8 \\
\hline
\end{tabular}

* Approximate value obtained according to a quadratic variation of the second order moments.

- With the load application, the most requested side (right one) tends to experience a greater loss of stiffness, due to material nonlinearities, such as concrete cracking, for example, and with this, a stress redistribution effect to less loaded, more integrated and more rigid regions (left edge), occurs;

- In the shear wall NL-FEA, it can be observed that the maximum displacement, perpendicular to the structure plane, Figure 10a, was located in a node close to the center of the most loaded edge (right one). Consequently, after this translation, associated with a wall lateral instability, it is expected that there will be an effect of forces redistribution to the left edge, relative to geometric non-linearity;

- In addition, as seen earlier, the Saint-Venant's principle tends to smooth the compression stress distribution, and thereby mitigate the second order localized effects on the structure.

This behavior is observed comparing the maximum moments at the midpoints of the two lateral edges, in the 100 load steps. In the initial steps, when nonlinearities are negligible, the two bending moments were practically the same, however, with the load increasing, there is a trend for the maximum bending moment in the left edge (less loaded) to 
be $27.6 \%$ higher than the same internal moment in the right edge. In the last load steps, the bending moment $M_{Y Y}$ on the left edge was equal to $35.6 \mathrm{kN} \cdot \mathrm{m} / \mathrm{m}$, while in the right one was $27.9 \mathrm{kN} \cdot \mathrm{m} / \mathrm{m}$, Table 2 .

In addition, the internal forces redistribution effect is also influenced by the higher reinforcement ratio on the shear wall lateral sides, which causes the trend of internal forces migrate from the center to the lateral elements. To verify this behavior, the simple planar wall was reanalyzed considering a uniformly distributed longitudinal reinforcement ratio $\left(23 \mathrm{~cm}^{2} / \mathrm{m}\right.$ per face). Thus, it was possible to observe that, even in this new situation, there is still a concentration of moments on the left edge, with intensity close to the original problem $(+28.0 \%)$. However, the magnitude of the internal forces is attenuated, being, in the last load step, a maximum equal to $33.8 \mathrm{kN} \cdot \mathrm{m} / \mathrm{m}$ on the left edge, and $26.4 \mathrm{kN} \cdot \mathrm{m} / \mathrm{m}$ on the right one.

A finite shell element linear-elastic analysis of this problem was realized using the SAP 2000 software [18], without considering the structure geometric non-linearity, and, assuming mesh and other criteria similar to those previously presented. In this study, it is also possible to see that there is a certain trend of bending moments concentrate in the two free lateral edges. This can also be verified analyzing uniformly loaded linear-elastic plates, and somehow, it agrees with item 20.2 of NBR-6118/2014 [2], which, in its figure 20.1, recommends the positioning of steel bars at the ends of free edges, in reinforced concrete slabs.

On the other hand, it is possible to observe that the transverse bending moment (tension in the horizontal direction) $M_{X X}$ is concentrated in the upper edge central region, Figure 10f, a behaviour that was also observed in the SAP 2000 linear-elastic analysis. The NL-FEA maximum moment $M_{X X}(4.8 \mathrm{kN} \cdot \mathrm{m} / \mathrm{m})$ is higher than the result provided by the grid method $(1.7 \mathrm{kN} \cdot \mathrm{m} / \mathrm{m})$ [3], Table 2. However, even so, $M_{X X}$ was less than $13.5 \%$ of $M_{Y Y}$ Thus, although the transverse and longitudinal reinforcements design are different, respectively, flexural design and combined axial load and bending design, and, $N_{Y Y}$ has a crucial role in the latter, the difference obtained between $M_{X X}$ and $M_{Y Y}$ strengthens the thought that the Brazilian code recommendation that considers the transverse reinforcement as $25 \%$ of the longitudinal one can be exaggerated in certain situations, as presented by França and Kimura [3].

Finally, the computational cost of the simple planar shear wall NL-FEA, according to the criteria adopted for the iterative-incremental method, had an average processing time of approximately equal to $40 \mathrm{~min}$, using a computer with an Intel Core i7-5500U CPU @ 2.40GHz processor. The computational cost observed can be considered high and makes this type of analysis less attractive for day-to-day work in the design office. However, it allows another perspective of the behavior of the structure and has fundamental importance for the engineering profession.

\subsection{U-shaped shear wall analysis results}

In the U-shaped shear wall, as well as in the previous problem, the stress redistribution effect, and the Saint-Venant principle, proved to be quite relevant, both in the symmetric and asymmetric buckling mode patterns. As can be seen in Figures $11 \mathrm{~d}$ and $12 \mathrm{~d}$, although the maximum compression loading is located in the elements of the upper corners of the lateral planar wall free edges, the normal stress along the shear wall height tends to be concentrated close to the central-lateral walls connections (the greatest stiffness structure region).

Similarly to what can be found in the literature [3], the transverse bending moment $M_{X X}$, in the two buckling modes, is practically negligible at the lateral planar walls lateral free edge, and gradually increases as the study point approaches the central-lateral walls connection, Figures $11 \mathrm{f}$ and $12 \mathrm{f}$. However, the bending moments found were less than the literature ones [3] (approximately 22.9\%), and had the opposite sign, in some regions, Figures 11f and 12f. This behavior inversion was also noticed in the structure displacements, Figures $11 \mathrm{c}$ and $12 \mathrm{c}$. Based on the bending moments $M_{X X}$ found, in the two buckling modes, neglecting the minimum flexural reinforcement, a very small transverse reinforcement ratio, in the order of $0.7 \mathrm{~cm}^{2} / \mathrm{m}$, can be obtained, approximately $6.3 \%$ of the longitudinal reinforcement. Again, the results obtained strengthen the thought that the shear wall minimal transverse reinforcement presented in the Brazilian code may be exaggerated in some cases.

With respect to the longitudinal bending moment $M_{Y Y}$, in addition to the fact that no internal forces concentration was observed on the lateral planar walls free edge, in the two buckling modes, in disagreement to what is reported in the literature [3], the moments found in this region had a negligible magnitude, Figures 11e and 12e, and the maximum moment was located close to the central-lateral walls connection, Table 3. A possible justification for the difference between this result and the literature comes from the smallest transverse displacement in the lateral walls, obtained in the two buckling modes $(0.064 \mathrm{~mm})$, Figures $11 \mathrm{c}$ and $12 \mathrm{c}$, which results in irrelevant second order localized effects. Again, it is presumed that the stress redistribution effect and the Saint-Venant's principle had a major role in smoothing of these nonlinear effects. 


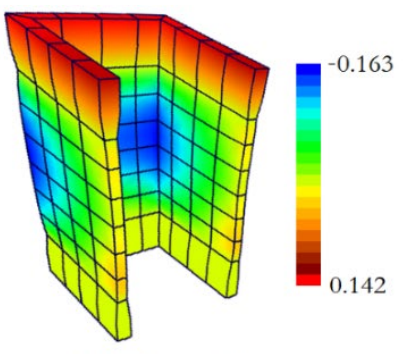

(a) Diplacement X (mm)

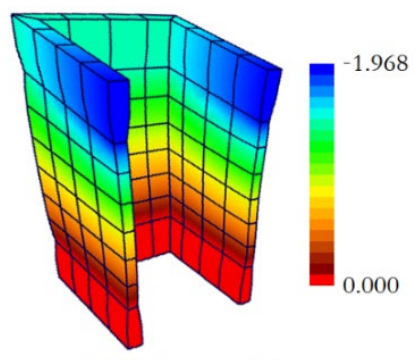

(b) Displacement Y (mm)

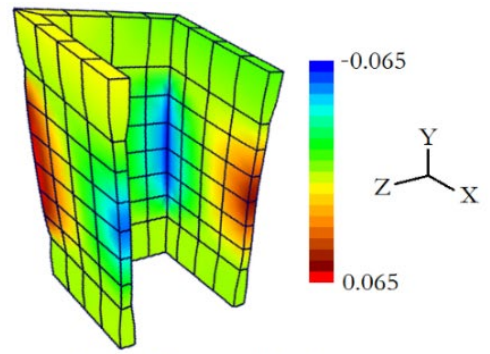

(c) Displacement Z (mm)
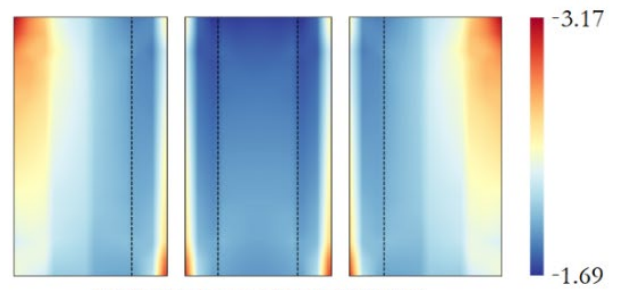

(d) Vertical normal force $(\mathrm{MN} / \mathrm{m})$

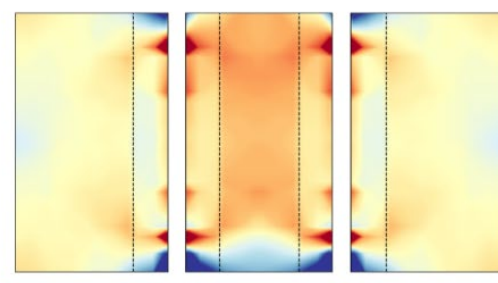

(e) Longitudinal bending moment $(\mathrm{kN} . \mathrm{m} / \mathrm{m})$
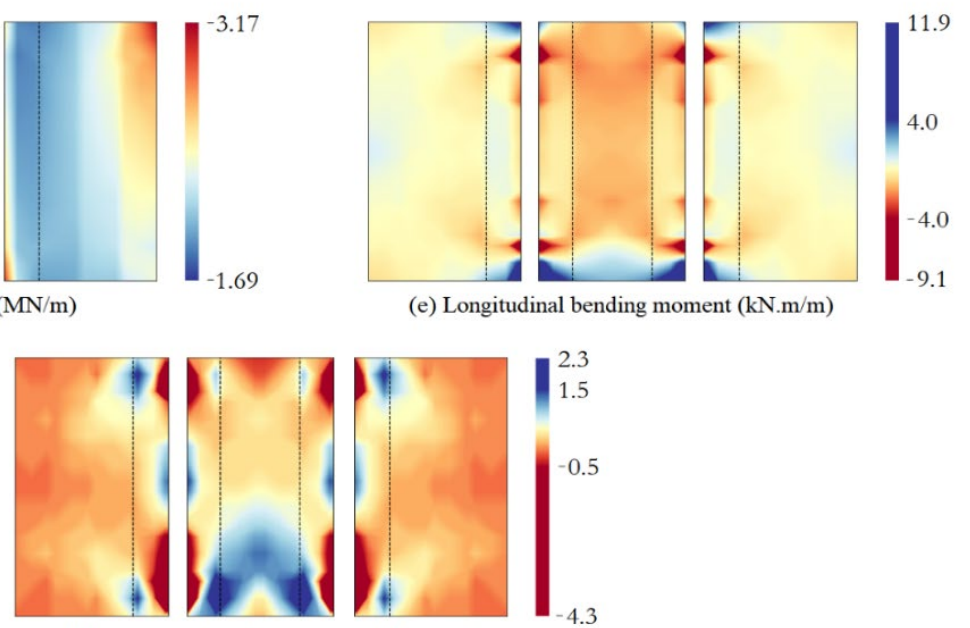

(f) Transverse bending moment $(\mathrm{kN} . \mathrm{m} / \mathrm{m})$

Figure 11. U-shaped shear wall displacements and internal forces diagrams (symmetric)

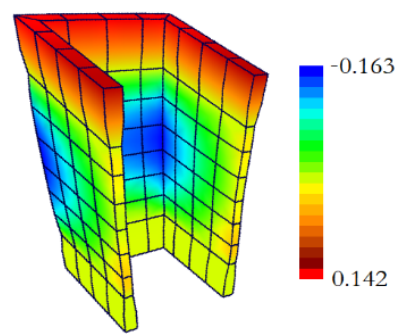

(a) Diplacement X (mm)

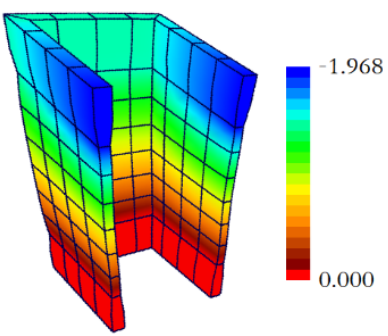

(b) Displacement Y (mm)

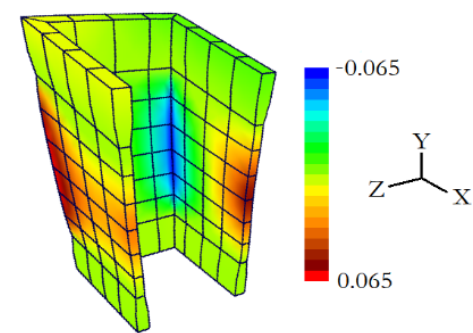

(c) Displacement Z (mm)

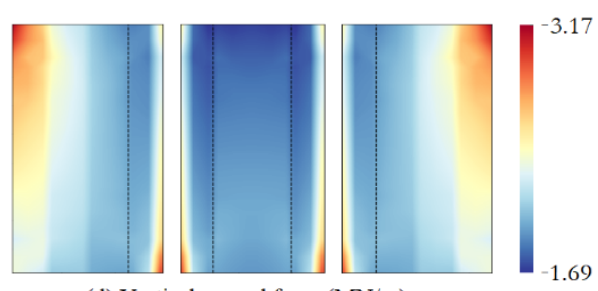

(d) Vertical normal force $(\mathrm{MN} / \mathrm{m})$

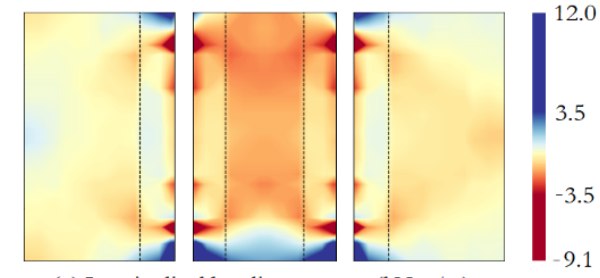

(e) Longitudinal bending moment $(\mathrm{kN} . \mathrm{m} / \mathrm{m})$

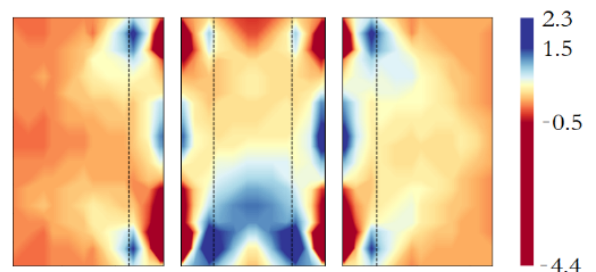

(f) Transverse bending moment $(\mathrm{kN} . \mathrm{m} / \mathrm{m})$

Figure 12. U-shaped shear wall displacements and internal forces diagrams (asymmetric) 
In addition, it was observed irregular internal forces distributions in $M_{X X}$ and $M_{Y Y}$, in the elements that form the central-lateral walls connection, Figures 11e and 11f. This atypical behavior can be associated with a way that the connection was modeled. Further studies are necessary to verify this structure modeling feature.

Table 3. U-shaped shear wall maximum bending moments $(\mathrm{kN} \cdot \mathrm{m} / \mathrm{m})$.

\begin{tabular}{ccc}
\hline & Longitudinal bending moment $\boldsymbol{M}_{\boldsymbol{Y}}$ & Transverse bending moment $\boldsymbol{M}_{\boldsymbol{X} \boldsymbol{X}}$ \\
\hline Brazilian code approximate procedure & $76.7 *$ & - \\
\hline [3] & $16.7 *$ & 19 \\
\hline Grid method [3], [10] & $11.9 * *$ & -4.3 \\
\hline $\begin{array}{c}\text { VecTor 4 NL-FEA (Symmetric } \\
\text { Buckling Mode) }\end{array}$ & $12.0 * *$ & -4.4 \\
\hline $\begin{array}{c}\text { VecTor 4 NL-FEA (Asymmetric } \\
\text { Buckling Mode) }\end{array}$ & 12.4 \\
\hline
\end{tabular}

* Located on the wall free edge. ${ }^{*}$ Located on the central-lateral walls connection.

In order to verify the results accuracy, analogous to the previous problem, a linear-elastic FEA was developed, using SAP 2000 software [18], assuming mesh and other modeling criteria similar to that presented previously. Thus, despite the simplicity of the model, it was possible to observe a qualitative behavior close to the NL-FEA, not only with respect to the displacements Z, Figures $11 \mathrm{c}$ and $12 \mathrm{c}$, but also to the other degrees of freedom. This corroborates to the reasonableness of the results obtained in the NL-FEA.

In addition, the SAP 2000 model was subjected to a buckling modes analysis, where it was possible to verify that the two modes studied in this paper are actually the structure most likely behaviors. The buckling factors (buckling load/real load ratio), for the symmetric and asymmetric modes were, respectively, 24.87 and 25.37. The other buckling modes proved to be of little practical interest, for example, the third mode (symmetrical buckling with double curvature) had a much higher buckling factor than the first two, about 46.6. The relatively high buckling factors obtained in SAP 2000 help to justify the absence of major structural instabilities in the VecTor 4 results.

Somehow, the response observed in the shear wall NL-FEA is similar to the behaviour of cold-formed steel frames subject to local buckling [19], [20]. According to Yu and LaBoube [21], it is possible to observe in this type of problem a stress redistribution from free edges to region with relatively greater stiffness (central-lateral connections). This apparent similarity between the two problems behaviors is a promising opportunity for scientific investigation.

As in the previous example, based on the iterative-incremental analysis criteria presented, it was possible to observe in this case a high processing time, approximately equal to three hours. Again, a computer with an Intel Core i7-5500U CPU @ 2.40GHz processor was used. Nevertheless, this type of analysis remains relevant due to the fact that it allows the shear wall behavior evaluation considering complex and important effects.

\subsection{Slender shear walls}

Finally, in order to evaluate the behavior of shear walls composed by slender planar segments, the two structures analyzed in this paper had some dimensions modified to obtain planar walls components with a slenderness ratio $(\lambda=90)$, NBR-6118: 2014 [2]. The first simple planar shear wall height was changed from 3 to 5.2 meters, while in the U-shaped shear wall, in addition to the height having been increased from 4.5 to $6.5 \mathrm{~m}$, it was necessary to expand the wall width from 3 to $4.3 \mathrm{~m}$, since, according to Case 2 of Table 1, the wall equivalent, and consequently its slenderness ratio, depends on both dimensions. The other structure geometric parameters, reinforcement ratios, external loads, finite element mesh, among other criteria, remained unchanged. With respect to the first shear wall, in general, as can be seen comparing Figures 10 and 13, the behavior in both situations is very close. However, with the increase of the shear wall length, and, consequently, of the element slenderness ratio, a growth can be observed both in the longitudinal and transverse bending moments, as well as in the displacements, mainly in the $\mathrm{Z}$ axis, as expected.

Regarding the second shear wall, comparing, respectively, Figures 11 and 14, and, Figures 12 and 15, as well as in the first shear wall, one can observe the similarity between the two situations. However, although the height of the element has been increased, and this contributes to increasing the wall slenderness, as the width of these elements has also been increased (keeping the external loads constant), a considerable decrease in internal forces can be observed in the structure, although the wall slenderness in this new situation is greater than in the previous case. 


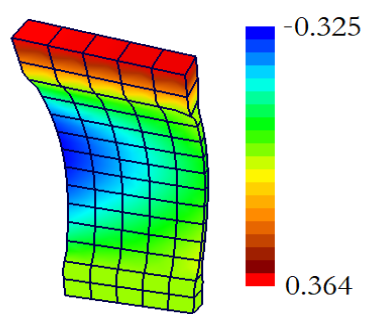

(a) Diplacement X (mm)

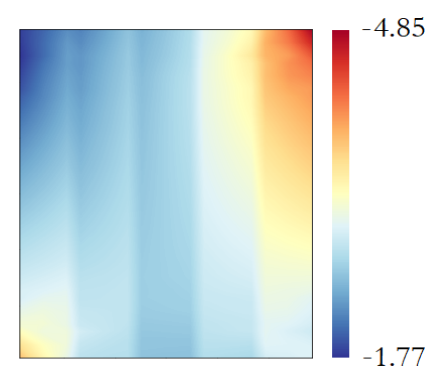

(d) Vertical normal force $(\mathrm{MN} / \mathrm{m})$

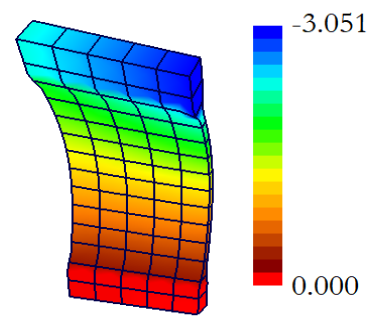

(b) Displacement Y (mm)

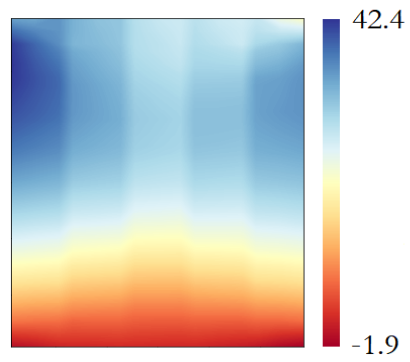

(e) Longitudinal bending moment $(\mathrm{kN} . \mathrm{m} / \mathrm{m})$

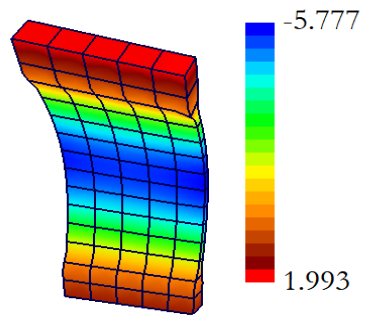

(c) Displacement Z (mm)

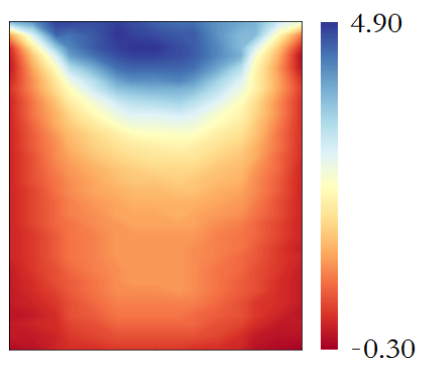

(f) Transverse bending moment $(\mathrm{kN} . \mathrm{m} / \mathrm{m})$

Figure 13. Simple planar shear wall displacements and internal forces diagrams, $\lambda=90$

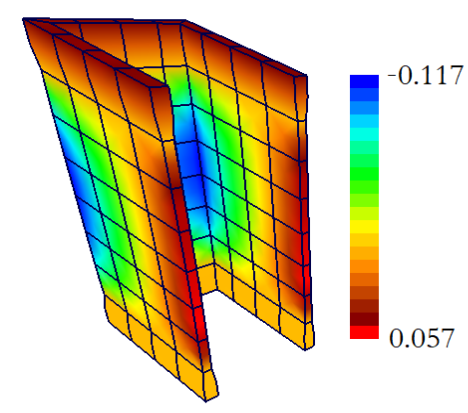

(a) Diplacement X (mm)

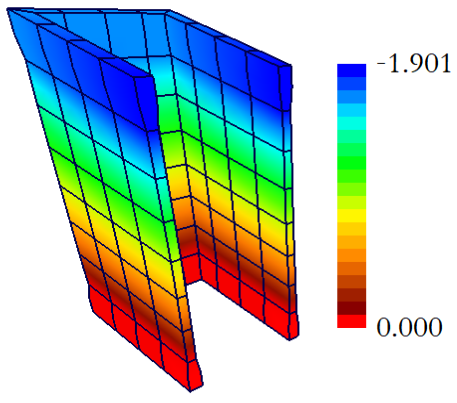

(b) Displacement Y ( $\mathrm{mm})$

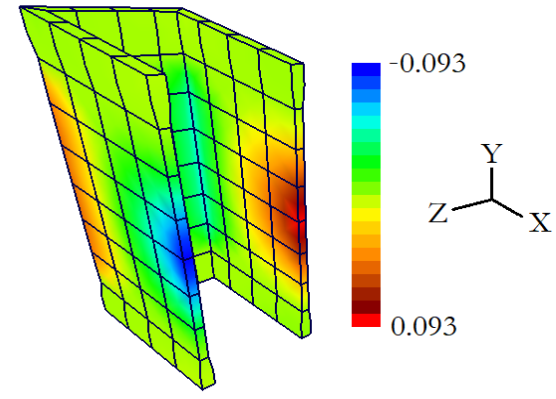

(c) Displacement Z (mm)

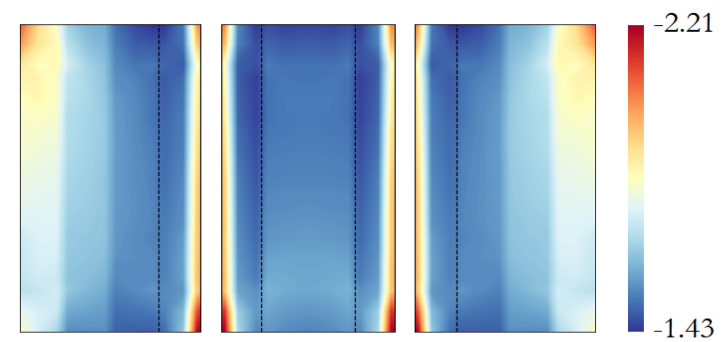

(d) Vertical normal force $(\mathrm{MN} / \mathrm{m})$

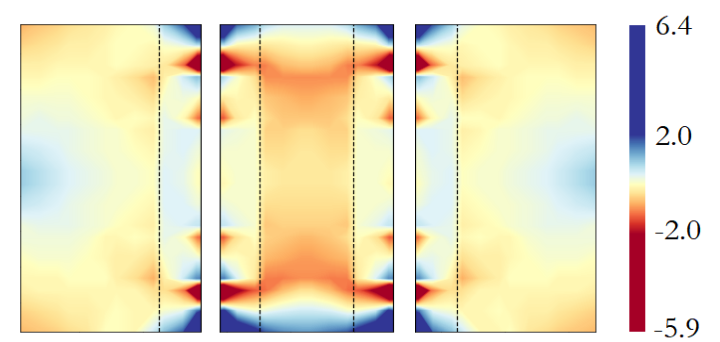

(e) Longitudinal bending moment $(\mathrm{kN} . \mathrm{m} / \mathrm{m})$

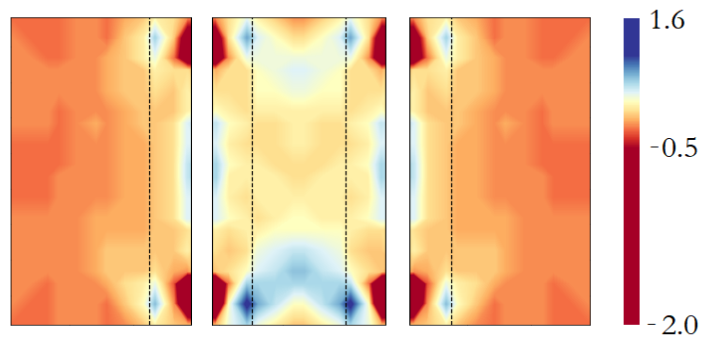

(f) Transverse bending moment (kN.m/m)

Figure 14. U-shaped shear wall results (symmetric), lateral planar wall segment $\lambda=90$ 


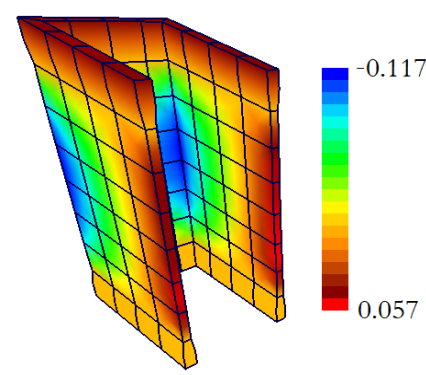

(a) Diplacement X (mm)

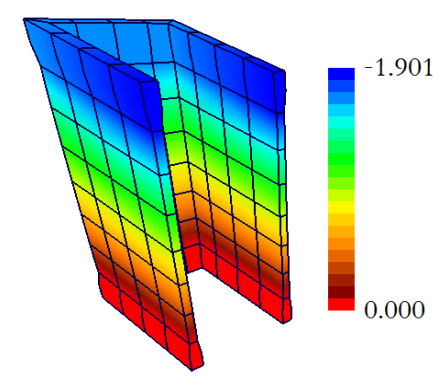

(b) Displacement Y (mm)

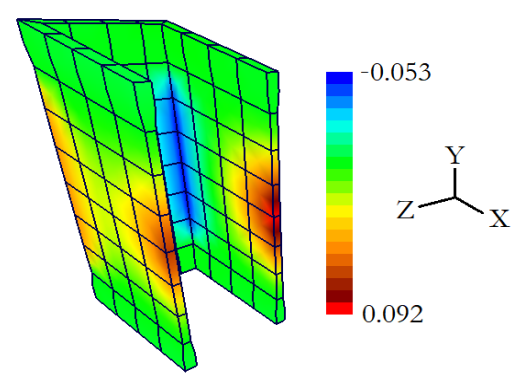

(c) Displacement Z (mm)

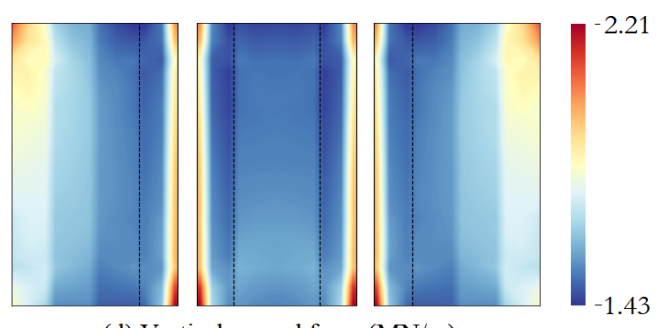

(d) Vertical normal force $(\mathrm{MN} / \mathrm{m})$

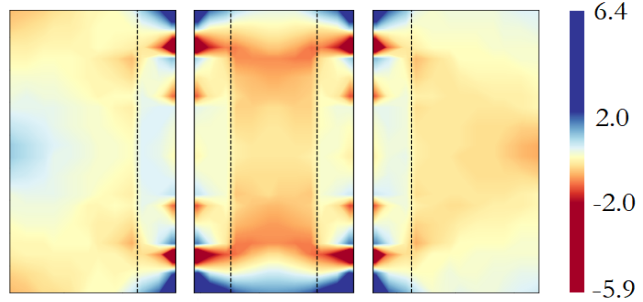

(e) Longitudinal bending moment $(\mathrm{kN} . \mathrm{m} / \mathrm{m})$

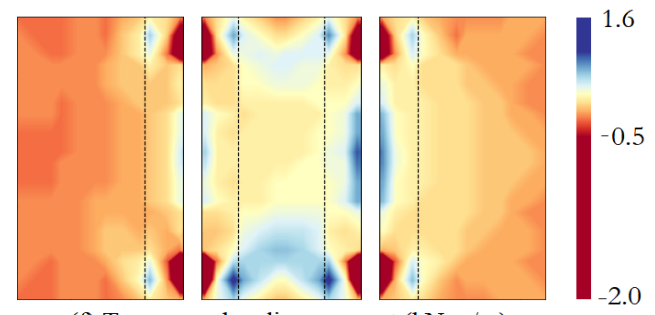

(f) Transverse bending moment $(\mathrm{kN} . \mathrm{m} / \mathrm{m})$

Figure 15. U-shaped shear wall results (asymmetric), lateral planar wall segment $\lambda=90$

These last results demonstrate the need to development of parametric studies of this problem, varying dimensions, reinforcement ratios, among other properties, in order to verify the practical design limits.

\section{CONCLUSIONS}

In this article, for two usual shear walls (simple planar and U-shaped), a comparative study between the structures behavior according to the Brazilian code approximate procedure [2], the grid method [3], and a material and geometric nonlinear finite shell element analysis (NL-FEA), performed in VecTor 4 software, based on the Modified Compression Field Theory (MCFT) [4]. In addition, the U-shaped shear wall NL-FEA was made considering the structure main buckling modes displacement patterns. The following can be highlighted:

- The stress redistribution effect and the Saint-Venant's principle proved to be an analysis main issue, being responsible for smoothing the shear walls second order localized effects, a fact that was not observed in the grid method or in the Brazilian code approximate procedure;

- In these analyses, the bending moments obtained led to relationships between the transverse and longitudinal reinforcements below 25\%, which suggests that the Brazilian code recommendation may be excessively conservative in some cases, as reported in the literature [3];

- With respect to the NL-FEA computational cost, according to the iterative-incremental method presented criteria, it was possible to observe an average processing time approximately equal to $40 \mathrm{~min}$, for the simple planar shear wall, and, three hours, for the U-shaped shear wall. However, despite the high cost make this methodology less attractive for day-to-day work in design offices, this type of approach allows another perspective with regard to structure behavior and has fundamental importance for the engineering profession.

- Finally, the apparent similarity between the behavior of U-shaped shear wall and cold-formed steel frames subjected to local buckling may represent an opportunity for scientific investigation. 


\section{REFERENCES}

[1] J. K. Wight and J. K. MacGregor, Reinforced Concrete: Mechanics \& Design, 6th ed. Upper Saddle River: Pearson, 2012.

[2] Associação Brasileira de Normas Técnicas, Projeto de Estruturas de Concreto - Procedimento, NBR 6118, 2014.

[3] R. L. S. França and A. E. Kimura, "Resultados de recentes pesquisas para o dimensionamento das armaduras longitudinal e transversal em pilares-parede,” in: An. $9^{\circ}$ Enc. Nac. Eng. Consult. Estrut., 2006.

[4] T. D. Hrynyk, "Behaviour and modelling of reinforced concrete slabs and shells under static and dynamic loads," Ph.D. dissertation, Dep. Civ. Eng., Univ. Toronto, Toronto, 2013.

[5] V. B. Almeida, "Dimensionamento, detalhamento e execução de pilares-parede," B.S. thesis, Dep. Eng. Civ., Univ. Fed. Pernambuco, Recife, 2018.

[6] M. C. B. N. Campos, “Análise numérica de pilares-parede de concreto armado com seção retangular,” DSc. thesis, Prog. Pós-grad. Eng. Civ., Dep. Eng. Civ., Univ. Fed. Pernambuco, Recife, 2016.

[7] Associação Brasileira de Normas Técnicas, Projeto de Estruturas Resistentes a Sismos - Procedimento, NBR 15421, 2006.

[8] J. M. Araújo, "Flambagem local dos pilares-parede de concreto armado," Rev. Teor. Prat. Eng. Civ., no. 9, pp. $29-37,2006$.

[9] Instituto Brasileiro do Concreto, Comentários e Exemplos de Aplicação da ABNT NBR 6118:2014, 2015.

[10] A. E. Kimura, Cálculo de Pilares de Concreto Armado - Introdução, Visão Geral \& Exemplos. São Paulo: Associação Brasileira de Engenharia e Consultoria Estrutural, 2016.

[11] T. J. R. Hughes and M. Cohen, "The Heterosis finite element for plate bending," Comput. Struc., vol. 9, pp. 445-450, 1978.

[12] D. R. J. Owen and J. A. Figueiras, "Ultimate load analysis of reinforced concrete plates and shells," In Finite Element Software for Plates and Shells, E. Hilton, D. R. J. Owen, Eds., Swansea, UK: Pineridge Press, 1984, pp. 403.

[13] F. J. Vecchio and M. P. Collins, "The modified compression field theory for reinforced concrete elements subjected to shear," $A C I$ Struct. J., vol. 83, no. 6, pp. 925-933, 1986.

[14] F. J. Vecchio, "Disturbed stress field model for reinforced concrete: formulation," J. Struct. Eng., vol. 126, no. 9, pp. 1070-1077, 2000.

[15] R. Park, M. J. N. Priestley, and W. D. Gill, "Ductility of square-confined concrete columns," J. Struct. Div., vol. 108, pp. 929-950, 1982.

[16] P. S. Wong, H. Trommels, and F. J. Vecchio, VecTor2 and FormWorks User's Manual, Technical Report, 2nd ed. Toronto: Dep. Civ. Eng., Univ. Toronto, 2012.

[17] M. Seckin, "Hysteretic behaviour of cast-in-place exterior beam-column-slab subassemblies," Ph.D. thesis, Dep. Civ. Eng., Univ. Toronto, Toronto, 1981.

[18] SAP 2000 v21. Computers and Structures, Inc., Walnut Creek, California, USA, 2000. [Online]. Available: csiamerica.com/products/sap2000.

[19] Associação Brasileira de Normas Técnicas, Projeto de Estruturas de Aço e de Estruturas Mistas de Aço e Concreto de Edifícios, NBR $8800,2008$.

[20] W. Pfeil and M. Pfeil, Estruturas de Aço - Dimensionamento Prático de Acordo com a NBR 8800:2008, 8th ed. Rio de Janeiro: LTC, 2009.

[21] W. Yu and H. LaBoube, Cold-Formed Steel Design, 4th ed. Hoboken: Wiley, 2010.

Author contributions: Jordlly Reydson de Barros Silva: conceptualization, methodology, numerical analysis, writing. Bernardo Horowitz: conceptualization, methodology, writing, supervision.

Editors: Osvaldo Luís Manzoli, José Luiz Antunes de Oliveira e Sousa, Guilherme Aris Parsekian. 